\title{
Phenotypic variability and population structure analysis of Tanzanian free-range local chickens
}

James R. Mushi', Gaspar H. Chiwanga', Esinam N. Amuzu-Aweh², Muhammed Walugembe, Robert A. Max', Susan J. Lamont ${ }^{3}$, Terra R. Kelly ${ }^{4}$, Esther L. Mollel', Peter L. Msoffe ${ }^{1}$, Jack Dekkers ${ }^{3}$, Rodrigo Gallardo ${ }^{4}$, Huaijun Zhou ${ }^{5}$ and Amandus P. Muhairwa ${ }^{1 *}$ (D)

\begin{abstract}
Background: Free-range local chickens (FRLC) farming is an important activity in Tanzania, however, they have not been well-characterized. This study aimed to phenotypically characterize three Tanzanian FRLCs and to determine their population structure. A total of 389 mature breeder chickens (324 females and 65 males) from three popular Tanzanian FRLC ecotypes (Kuchi, Morogoro-medium and Ching'wekwe) were used for the phenotypic characterization. Progenies of these chickens were utilized to assess population structure. The ecotypes were collected from four geographical zones across Tanzania: Lake, Central, Northern and Coastal zones. Body weights and linear measurements were obtained from the mature breeders, including body, neck, shanks, wingspan, chest girth, and shank girth. Descriptive statistics were utilized to characterize the chickens. Correlations between the linear measurements and differences among the means of measured linear traits between ecotypes and between sexes were assessed. A total of 1399 progeny chicks were genotyped using a chicken $600 \mathrm{~K}$ high density single nucleotide polymorphism (SNP) panel for determination of population structure.
\end{abstract}

Results: The means for most traits were significantly higher in Kuchi relative to Ching'wekwe and Morogoromedium. However, shank length and shank girth were similar between Kuchi and Morogoro-medium females. All traits were correlated with the exception of shank girth in Morogoro-medium. Admixture analyses revealed that Morogoro-medium and Ching'wekwe clustered together as one population, separate from Kuchi.

Conclusions: Phenotypic traits could be used to characterize FRLCs, however, there were variations in traits among individuals within ecotypes; therefore, complementary genomic methods should be considered to improve the characterization for selective breeding.

Keywords: Free-range local chickens, Phenotypic diversity, Genetic diversity, Population structure

\footnotetext{
*Correspondence: apm@sua.ac.tz

'Department of Veterinary Medicine and Public Health, Sokoine University of Agriculture, Morogoro, Tanzania

Full list of author information is available at the end of the article
}

(C) The Author(s). 2020 Open Access This article is licensed under a Creative Commons Attribution 4.0 International License, which permits use, sharing, adaptation, distribution and reproduction in any medium or format, as long as you give appropriate credit to the original author(s) and the source, provide a link to the Creative Commons licence, and indicate if changes were made. The images or other third party material in this article are included in the article's Creative Commons licence, unless indicated otherwise in a credit line to the material. If material is not included in the article's Creative Commons licence and your intended use is not permitted by statutory regulation or exceeds the permitted use, you will need to obtain permission directly from the copyright holder. To view a copy of this licence, visit http://creativecommons.org/licenses/by/4.0/ The Creative Commons Public Domain Dedication waiver (http://creativecommons.org/publicdomain/zero/1.0/) applies to the data made available in this article, unless otherwise stated in a credit line to the data. 


\section{Background}

Poultry plays an important role in the livelihoods [1] of communities in Africa. It is among the most prevalent livestock produced in Tanzania, and chickens account for approximately $94 \%$ of poultry raised by farmers [2]. Free-range local chickens (FRLCs) have been produced in Tanzania for many years [3]. In rural communities, the production is mainly for subsistence [2, 4]. Commercial poultry production is common in urban areas where farmers typically raise exotic breeds in intensive systems.

The FLRCs are relatively adapted to and resilient to stressful conditions, including harsh weather and disease [5-8]. They can be produced with minimal resources, such as shelter, feed, and veterinary services. As a result, they serve as important sources of animal protein and household income, especially for resourcepoor marginalized rural communities. The FRLCs and their products are also socially and culturally accepted across different Tanzanian communities. Despite their importance, research on improving productivity of the FRLCs is lacking [9]. Tanzania has over 17 ecotypes of indigenous chickens $[10,11]$. Most of these ecotypes have not been well-characterized and their production potential is poorly understood.

There are several methods used to characterize animals ranging from linear measurement of morphological traits to the use of molecular techniques [12]. For instance, morphological measurements have been used to characterize and compare various poultry breeds [13, 14] and microsatellites have been used to determine the origin of African chickens [15-17]. In addition, single nucleotide polymorphism (SNP) makers have been used to compare the best method for ascertaining diversity among chickens [18], to cluster the genomes of commercial and non-commercial chicken breeds [19] and to investigate the genetic structure of chicken populations [20]. Climatic conditions and other stressors are highly variable across Tanzania. As a result, FRLC populations may develop different adaptation mechanisms leading to spatial differences in population structure. The extensive management system used to rear FRLCs also allows for random mating leading to panmictic populations [21] with no clearly defined chicken types, strains or lines. The aim of this study was to characterize three Tanzanian
FRLC ecotypes using linear body measurements and population structure analysis. Information generated through this study will inform on selection programs to improve FRLC production in Tanzania.

\section{Results}

\section{Phenotype characterization}

The results of the effects of chicken ecotype and sex on the morphometric and body weight measurement traits are presented in Table 1. Both ecotype and sex effects had a significant influence on traits with the exception of shank girth (SG). Interactions between sex and ecotype effects were only significant for the CG, WS and SL. Males were also significantly different from females for the BL, NL, CG, WS and BW measurements. Similarly, there were significant differences between ecotypes for the BL, NL, CG, WS, SL and BW. Least square means (LSmeans) of the body measurements along with their standard errors $( \pm S E)$ are shown in Table 2. The Kuchi ecotype had higher mean values for $\mathrm{BL}, \mathrm{NL}$, and $\mathrm{BW}$ measurements compared to Ching'wekwe and Morogoro-medium ecotypes, and measurements for these traits were significantly higher in male chickens. The LSmeans for the CG, WS and SL were significantly higher in males across all ecotypes. For the Morogoro-medium chickens, the LSmean for the SL was higher in males, but the difference was not statistically significant. Significant differences in LSmeans for the BL, NL and BW were detected across the ecotypes with the highest LSmeans in Kuchi, followed by Morogoromedium and Ching'wekwe. There were no significant differences in the SG between sexes across the ecotypes. Overall, males had higher mean measurements across the ecotypes. However, there was individual variation within ecotypes for both sexes that were beyond the means of the ecotypes, where measurements overlapped with other ecotypes. These results indicate that Kuchi chickens were heavier and longer/taller than Morogoro-medium and Ching'wekwe chickens were the shortest and lightest. Linear measurements and body weights within each ecotype were positively correlated except for Morogoro-medium where the SG showed no significant correlation with any other traits (Tables 3, 4 and 5).

Table 1 Analysis of variance $p$-values for measured traits as affected by the ecotype and sex

\begin{tabular}{llllllll}
\hline Effects & $\mathrm{BL}$ & $\mathrm{NL}$ & $\mathrm{CG}$ & $\mathrm{WS}$ & $\mathrm{SL}$ & SG \\
\hline Ecotype & $<2 \mathrm{e}-16^{* * *}$ & $<2 \mathrm{e}-16^{* * *}$ & $<2 \mathrm{e}-16^{* * * *}$ & $<2 \mathrm{e}-16^{* * *}$ & $<2 \mathrm{e}-16^{* * *}$ & 0.1266 & $<2 \mathrm{e}-16^{* * *}$ \\
Sex & $<2 \mathrm{e}-16^{* * *}$ & $<2 \mathrm{e}-16^{* * *}$ & $<2 \mathrm{e}-16^{* * *}$ & $<2 \mathrm{e}-16^{* * *}$ & $<2 \mathrm{e}-16^{* * *}$ & 0.0577. & $<2 \mathrm{e}-16^{* * *}$ \\
Ecotype: sex & 0.526 & 0.526 & $0.0106^{* *}$ & $0.0194^{*}$ & $0.000000678^{* * *}$ & 0.7096 & 0.426 \\
\hline
\end{tabular}

BL Body length, NL Neck length, CG Chest girth, WS Wingspan, SL Shank length, SG Shank girth, BW Body weight, ${ }^{* * *} p<0.001,{ }^{* *} p \leq 0.01,{ }^{*} p \leq 0.05$ 
Table 2 Least square means (LSmeans \pm SE) with standard error of measured traits among the FRLC

\begin{tabular}{|c|c|c|c|c|}
\hline \multirow[t]{2}{*}{ Trait } & \multirow[t]{2}{*}{ Sex } & \multirow[b]{2}{*}{ Kuchi } & \multicolumn{2}{|l|}{ Ecotype } \\
\hline & & & Ching'wekwe & Morogoro- medium \\
\hline \multirow[t]{2}{*}{$\overline{\mathrm{BL}}$} & $M$ & $50.9 \pm 0.62^{a}$ & $46.1 \pm 0.95^{b}$ & $48.30 \pm 0.41^{c, f}$ \\
\hline & $\mathrm{F}$ & $45.2 \pm 0.48^{\mathrm{a}, \mathrm{d}}$ & $43.7 \pm 0.22^{b, e}$ & $46.80 \pm 0.72^{c}$ \\
\hline \multirow[t]{2}{*}{$\mathrm{NL}$} & M & $19.4 \pm 0.54^{a}$ & $17.0 \pm 0.54^{b}$ & $17.40 \pm 0.28^{c, f}$ \\
\hline & $\mathrm{F}$ & $18.0 \pm 0.29^{a, d}$ & $15.8 \pm 0.17^{b, e}$ & $16.70 \pm 0.45^{c}$ \\
\hline \multirow[t]{2}{*}{ CG } & M & $35.30 \pm 0.59^{a}$ & $31.1 \pm 0.45^{b}$ & $34.0 \pm 0.25^{c, f}$ \\
\hline & $\mathrm{F}$ & $29.30 \pm 0.20^{a, d}$ & $29.0 \pm 0.17^{b, e}$ & $31.86 \pm 0.44^{c}$ \\
\hline \multirow[t]{2}{*}{ WS } & M & $47.7 \pm 0.78^{\mathrm{a}}$ & $43.1 \pm 0.75^{b}$ & $42.74 \pm 0.55^{c}$ \\
\hline & $\mathrm{F}$ & $45.7 \pm 0.82^{a, d}$ & $40.0 \pm 0.47^{\mathrm{b}, \mathrm{e}}$ & $42.60 \pm 0.77^{c, f}$ \\
\hline \multirow[t]{2}{*}{$S L$} & M & $11.4 \pm 0.28^{\mathrm{a}}$ & $10.2 \pm 0.25^{b}$ & $10.30 \pm 0.16^{c}$ \\
\hline & $\mathrm{F}$ & $10.5 \pm 0.16^{a, d}$ & $9.0 \pm 0.09^{\mathrm{b}, \mathrm{e}}$ & $9.90 \pm 0.19^{c}$ \\
\hline \multirow[t]{2}{*}{ SG } & M & $5.1 \pm 0.17^{\mathrm{a}}$ & $4.1 \pm 0.12^{\mathrm{a}}$ & $4.6 \pm 0.06^{\mathrm{a}}$ \\
\hline & $\mathrm{F}$ & $4.7 \pm 0.06^{a}$ & $3.9 \pm 0.04^{\mathrm{a}}$ & $4.4 \pm 0.13^{\mathrm{a}}$ \\
\hline \multirow[t]{2}{*}{ BW } & M & $2152.4 \pm 50.25^{a, d}$ & $1687.6 \pm 84.02^{b}$ & $2090.4 \pm 38.55^{c, f}$ \\
\hline & $\mathrm{F}$ & $1575.47 \pm 91.37^{\mathrm{a}}$ & $1162.5 \pm 30.65^{b, e}$ & $1455.7 \pm 68.23^{c}$ \\
\hline
\end{tabular}

Same superscript small letters indicate no significant difference between mean measurements. First superscript small letters compare among ecotype where the second superscript small letter compares between sex. $M$ males and $F$ females, BL Body length, NL Neck length, CG Chest girth, WS Wingspan, SL Shank length, SG Shank girth, BW Body weight

\section{Population structure evaluation}

The admixture analysis for the genetic population structure of the selected Tanzanian FRLC using SNP genotypes indicated evidence of admixture among the FRLC ecotypes (Fig. 1). From the analysis, the three chickens' ecotypes clustered into two populations instead of distinct three ecotypes. The Ching'wekwe and Morogoromedium ecotypes had higher average population proportions of population two ( 0.78 and 0.75 for Ching'wekwe and Morogoro-medium, respectively), compared to Kuchi that had a higher average proportion (0.67) of population one as shown in Table 6. Admixture population structure results were supported by the multi-dimensional scaling (MDS) plot (Fig. 2), with Ching'wekwe and Morogoro-

Table 3 Correlations among measured traits in Kuchi ecotype at $p \leq 0.05$

\begin{tabular}{llllllll}
\hline Measured trait & $\mathrm{BL}$ & $\mathrm{NL}$ & $\mathrm{CG}$ & $\mathrm{WS}$ & $\mathrm{SL}$ & $\mathrm{SG}$ & $\mathrm{BW}$ \\
\hline $\mathrm{BL}$ & 1 & & & & & & \\
$\mathrm{NL}$ & $0.8^{* * *}$ & 1 & & & & & \\
$\mathrm{CG}$ & $0.75^{* * *}$ & $0.68^{* * *}$ & 1 & & & & \\
WS & $0.77^{* * *}$ & $0.75^{* * *}$ & $0.77^{* * *}$ & 1 & & & \\
SL & $0.83^{* * *}$ & $0.77^{* * *}$ & $0.78^{* * *}$ & $0.85^{* * *}$ & 1 & & \\
SG & $0.78^{* * *}$ & $0.68^{* * *}$ & $0.87^{* * *}$ & $0.75^{* * *}$ & $0.77^{* * *}$ & 1 & \\
BW & $0.76^{* * *}$ & $0.62^{* * *}$ & $0.808^{* * *}$ & $0.63^{* * *}$ & $0.67^{* * *}$ & $0.83^{* * *}$ & 1 \\
\hline
\end{tabular}

$B L$ Body length, NL Neck length, CG Chest girth, WS Wingspan, SL Shank length, SG Shank girth, BW Body weight, ${ }^{* *} p<0.001$
Table 4 Correlations among measured traits in Ching'wekwe ecotype at $p \leq 0.05$

\begin{tabular}{llllllll}
\hline Measured trait & $\mathrm{BL}$ & $\mathrm{NL}$ & $\mathrm{CG}$ & WS & $\mathrm{SL}$ & $\mathrm{SG}$ & $\mathrm{BW}$ \\
\hline $\mathrm{BL}$ & 1 & & & & & & \\
$\mathrm{NL}$ & $0.65^{* * *}$ & 1 & & & & & \\
$\mathrm{CG}$ & $0.62^{* * *}$ & $0.41^{* * *}$ & 1 & & & & \\
$\mathrm{WS}$ & $0.43^{* * *}$ & $0.39^{* * *}$ & $0.34^{* * *}$ & 1 & & & \\
$\mathrm{SL}$ & $0.57^{* * *}$ & $0.45^{* * * *}$ & $0.34^{* * *}$ & $0.47^{* * *}$ & 1 & & \\
$\mathrm{SG}$ & $0.71^{* * *}$ & $0.53^{* * *}$ & $0.64^{* * *}$ & $0.36^{* * *}$ & $0.36^{* * *}$ & 1 & \\
BW & $0.69^{* * *}$ & $0.42^{* * *}$ & $0.77^{* * *}$ & $0.38^{* * *}$ & $0.45^{* * *}$ & $0.8^{* * *}$ & 1 \\
\hline BL Body length, NL Neck length, CG Chest girth, WS Wingspan, SL Shank & \\
length, SG Shank girth, BW Body weight, ${ }^{* * *} p<0.001$ & & &
\end{tabular}

medium clustering more closely together compared to Kuchi.

\section{Discussion}

This study was designed to evaluate linear measurements which could be used to phenotypically characterize three selected Tanzanian FRLC ecotypes based on their morphometrics, key criteria that farmers in Tanzania use to select chickens for breeding purposes. Further, it aimed to enhance understanding of the population structure of the selected FRLC ecotypes using single nucleotide polymorphism (SNP) genetic markers. These results provide a deeper insight into population structure of the FRLCs to complement the use of phenotypic selection. Proper characterization of the FRLC ecotypes, which has not been previously performed due to a lack of known parent stock and reliable source of dayold chicks [22], will promote their commercialization while improving their productivity through aiding in genetic selection of higher performing chickens. In this study, measurements of the BL, NL, CG, SL, SG, WS and BW were evaluated and compared among Kuchi, Ching'wekwe and Morogoro-medium Tanzanian FRLC ecotypes. Ecotype and sex had a significant influence on most of the physical measurements of the chickens (Table 1), similar to observations by Alabi et al. [12] for

Table 5 Correlations among measured traits in Morogoromedium ecotype at $p \leq 0.05$

\begin{tabular}{llllllll}
\hline Measured trait & $\mathrm{BL}$ & $\mathrm{NL}$ & $\mathrm{CG}$ & $\mathrm{WS}$ & $\mathrm{SL}$ & $\mathrm{SG}$ & $\mathrm{BW}$ \\
\hline $\mathrm{BL}$ & 1 & & & & & \\
$\mathrm{NL}$ & $0.57^{* * *}$ & 1 & & & & & \\
$\mathrm{CG}$ & $0.75^{* * *}$ & $0.46^{* * *}$ & 1 & & & & \\
WS & $0.74^{* * *}$ & $0.55^{* * *}$ & $0.69^{* * *}$ & 1 & & & \\
SL & $0.72^{* * *}$ & $0.59^{* * *}$ & $0.66^{* * *}$ & $0.85^{* * *}$ & 1 & & \\
SG & 0.09 & 0.04 & 0.07 & 0.1 & 0.07 & 1 & \\
BW & $0.74^{* * *}$ & $0.41^{* * *}$ & $0.91^{* * *}$ & $0.66^{* * *}$ & $0.62^{* * *}$ & 0.11 & 1 \\
\hline
\end{tabular}

BL Body length, NL Neck length, CG Chest girth, WS Wingspan, SL Shank length, SG Shank girth, BW Body weight, ${ }^{* *} p<0.001$ 


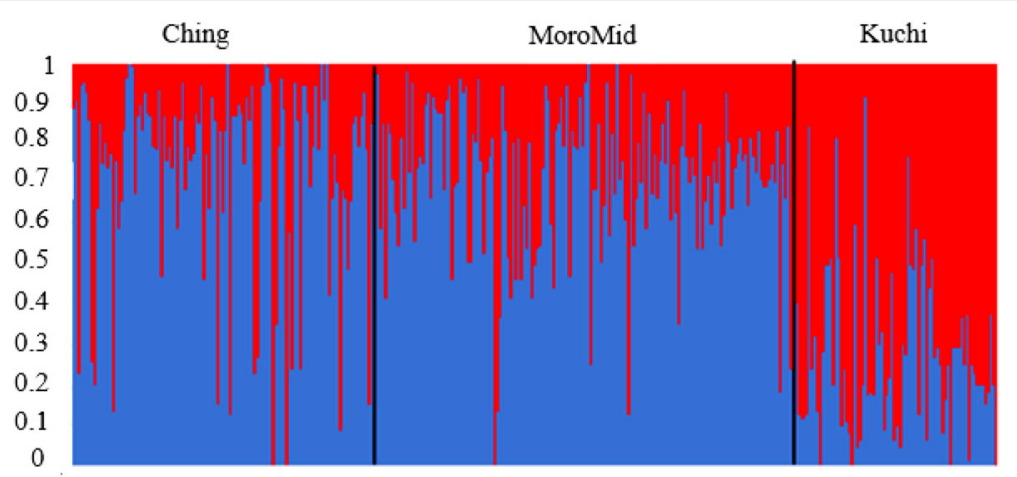

Fig. 1 Admixture analysis plot showing mixed ancestry among individuals for the three chicken ecotypes; Ching = Ching'wekwe, MoroMid= Morogoro-medium, Kuchi = Kuchi (Source- Walugembe et al., 2019)

indigenous chickens in South Africa. The males in all groups had the highest mean scores for all the measurements compared to the females (Table 2).

In this study, the Kuchi ecotype had relatively higher mean values for most of the measured traits as compared to the Ching'wekwe and Morogoro-medium ecotypes for both sexes. Ching'wekwe had the least mean values for all measurements. The findings in this study are similar to findings by Lweramila et al. [4] who compared the performance of Kuchi and Morogoro-medium under pure extensive management systems as well as findings by Magonka et al. [23] which revealed that Kuchi had the highest scores for most measurements compared to Horasi, Naked-neck and Frizzled ecotypes. Based on the results and the physical appearance of the chickens, the Ching'wekwe were shorter than Morogoromedium and Kuchi, probably owing to their proportionately shorter shanks and body parts. Kuchi on the other hand were observed to have a higher upright stature than the other two ecotypes. Apart from the observed mean variations between ecotypes, there were also large variations observed within ecotypes such that there are some individuals within each group that fell into extremes beyond the group means, thus, overlapping with individuals in other groups. The extreme measurements seen with some individual birds might be a result of random mating in the extensive free-ranging system that leads to admixtures of genotypes and that might have produced the intermediary traits observed in these individuals.

Table 6 Average proportions of admixture per ecotype

\begin{tabular}{lll}
\hline Chicken ecotype & Proportions $(\mathrm{K}=2)$ & \\
\cline { 2 - 3 } & Population1 & Population2 \\
\hline Ching'wekwe & 0.78 & 0.22 \\
Kuchi & 0.33 & 0.67 \\
Morogoro-medium & 0.75 & 0.25 \\
\hline
\end{tabular}

Body weights at maturity were also measured among the chicken types to complement the characterization. The results of this study corroborate previous findings by Lweramila at al [4] and Lyimo et al. [17] working with chickens in an extensive husbandry system where Kuchi weighed more than the other FRLC types. As expected, the males had higher mean body weights than the females as observed in many feeding trials [24]. However, some females in the current study had higher weights than males, probably due to changes in body physiology during laying periods whereby there is increase in the uterus size, fat deposition and increased feed intake [25]. Correlation analyses among the measured traits within ecotypes were positive and high for all traits in Kuchi and Morogoro-medium similar to observations by Alabi et al. [12]. However, there was no significant correlation between the SG and other measured body traits (Table 5). Results of the measurable phenotypic features used in this study could place the chickens into three suggestive ecotypes as they are known from their places of origin suggesting that phenotypic measurable features observed in mature FRLC may be used to complement other methods for identification of chicken ecotypes, especially among the three ecotypes used in this study.

The population structure analysis using admixture analysis placed the three selected FRLC ecotypes into strata of two populations instead of three ecotypes as initially perceived from the phenotypic study. A similar study using microsatellite genetic markers from five Tanzania local chicken ecotypes (Unguja, Pemba, Ching'wekwe, Morogoro-medium and Kuchi), [17] revealed similar findings in which Ching'wekwe and Morogoro-medium clustered together as one population while Kuchi stood as a separate population. Ching'wekwe and Morogoro-medium are found in areas with similar climatic conditions with no natural separation between the chicken types (Fig. 3). The lack of geographic barriers, the purchase of seeder flocks from region to region and 


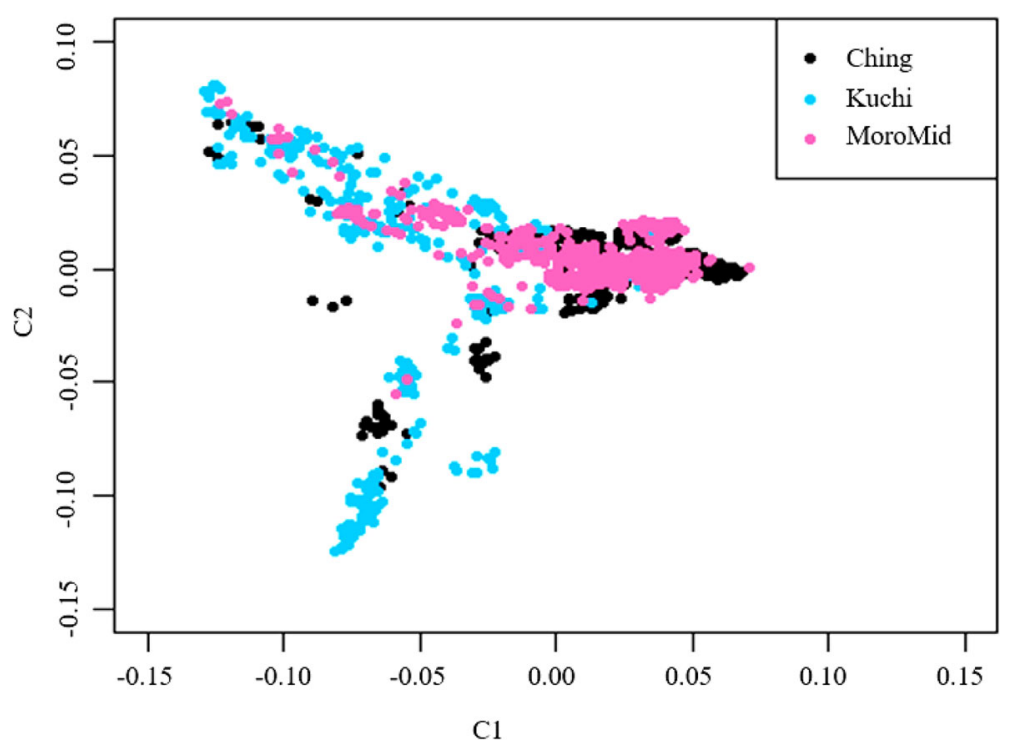

Fig. 2 Multi-dimensional scaling (MDS) plot showing the distribution of chickens in three clusters of the sampled population. Ching = Ching'wekwe, MoroMid = Morogoro-medium, Kuchi = Kuchi (Source- Walugembe et al., 2019)

the free-range management system of the FRLC in Tanzania might have increased the chances of interbreeding between these two ecotypes resulting in one population rather than two. The Kuchi are more adapted to regions of the Lake and Central zones which are cooler and more humid regions than the Morogoro and Tanga regions where the Ching'wekwe and Morogoro-medium ecotypes are adapted. Studies by Oka et al. [26] revealed that the Shamo chicken types of the Shikoku islands and Kuchi share the same mitochondrial DNA haplotypes. Also, Komiyama et al. [27] reported that the conformation of Kuchi beak is hooked or parrot-like and sharp like the
Shamo chickens of Japan. These studies suggest that the Kuchi chickens might have originated from Japan and formed a breeding colony in the Lake and Central zones where they are adapted. Further, research by Lyimo et al. [17] into the origins of Tanzanian local chickens using microsatellite markers found that the Kuchi are the least genetically diverse chicken type among five Tanzanian chickens investigated in the study.

\section{Conclusions}

With an exception of the SG, the mean linear measurements of traits used in the current study were significantly
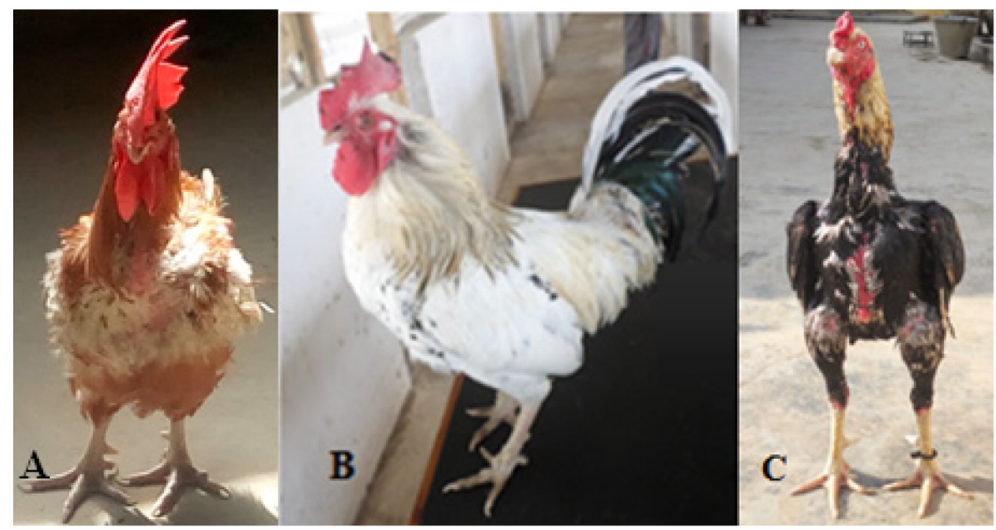

Fig. $\mathbf{3}$ a, b and c are Ching'wekwe, Morogoro-medium and Kuchi chicken ecotypes respectively 
different between ecotypes. This indicates that phenotypic trait can be used to identify the different chicken ecotypes. The strong correlations among the linear measurements show that selection for one trait means a selection for the other traits, with the exception of SG in the Morogoromedium ecotype, which was poorly correlated with other traits.

Individual variation in the measurements within ecotypes with overlap of extreme values between ecotypes was observed, making it difficult to predict a chicken's ecotype. As a result, additional information such as history should be used to complement the phenotypic characterization. However, from the results, it is difficult to use phenotypic measurable features to assign the FRLC to a particular genetic chicken population. Thus, the selection of FRLC for breeding purposes would be more canonical with use of genomic tools compared to the customary phenotypic methodologies in use by the FRLC farmers in the country.

\section{Methods}

Procedures for handling the experimental animals were approved by the Institutional Animal Care and Use Committee (IACUC) of the University of California Davis (\# 20831).

\section{Study area}

Experiments were conducted at Sokoine University of Agriculture (SUA) in Morogoro, Tanzania using facilities of the Department of Animal, Aquaculture and Range Sciences (DAARS). Three Tanzanian FRLC ecotypes (Kuchi, Ching'wekwe and Morogoro-medium) (Fig. 3) were randomly sampled from different zones with varying climatic conditions across the Tanzania mainland. The locations and weather conditions of the different regions and zones are shown in Table 7 . Ching'wekwe and Morogoro-medium were sampled from regions in close proximity (Morogoro and Tanga regions) to the Coastal and Northern zones; whilst Kuchi were sampled from the Lake and Central zones (Mwanza and Singida regions; Fig. 4) [28].

\section{Experimental chickens}

A flock of 389 FRLCs (324 females and 65 males) of the three ecotypes were randomly collected from village households in four regions of Tanzania (Tanga, Morogoro, Singida, and Mwanza regions) and were used to establish a breeding parent stock. Identification of chicken ecotypes was performed as previously described by Msoffe et al., and Guni and Katule [10, 11]. Each chicken was marked with a numbered aluminium wing tag. For each chicken ecotype, a male was placed separately in a pen with 6 to 10 females in a deep litter floor pen. The parent flocks were fed on maize-based layer diets with ad libitum access to water. Routine vaccinations against endemic diseases (Newcastle disease and infectious bursal disease) were administered [29, 30]. Worm infestations, ectoparasites and coccidiosis were treated/ controlled using anthelmintics (piperazine $\mathrm{DiHCl}^{\circ}$, Kepro, Holland), pesticides (imidacloprid Confidor', Bayer, Holland), and coccidiostats (Trisulmycine ${ }^{\circ}$ Laprovet, France), respectively.

\section{Progeny generation chickens}

Experimental chicken progenies were established using eggs collected from the parent stock for up to 10 consecutive days. The eggs were labelled with numbers corresponding to a sire and temporarily stored at $18{ }^{\circ} \mathrm{C}$ before incubation at $60 \%$ humidity and $37^{\circ} \mathrm{C}$. On day 18 postincubation, the eggs were transferred to a hatcher with special racks with cubical separations corresponding to sire identity to avoid mixing of chick progenies at hatching. Day old chicks were wing-tagged, weighed and transferred to a bio-secure deep litter floored experimental chicken house where they were fed on commercial chick mash and ad-libitum water access. Treatment for coccidiosis was performed as needed to control outbreaks in the flock. A total of 1399 chicks (477 Ching'wekwe, 315 Kuchi, and 607 Morogoro-medium) were produced following five rounds of incubation and hatching for use in the population structure analysis of the three FRLC ecotypes.

\section{Phenotypic linear measurements}

Linear measurements were obtained from chickens older than six months (mature chickens) and were performed

Table 7 Regional sources of parent stock FRLC

\begin{tabular}{llllll}
\hline FRLC & Regions & Location (DD) & Altitude $(m)$ & Av. Temp $\left({ }^{\circ} \mathrm{C}\right)^{\mathrm{a}}$ & Av. Humidity $(\%)^{\mathrm{b}}$ \\
\hline Ching'wekwe & Morogoro & $-5.5^{\circ}, 34.5^{\circ}$ & 213 & 24.6 & $75 \%$ \\
& Tanga & $-5.0667^{\circ}, 39.1^{\circ}$ & 22 & 28.0 & $76 \%$ \\
Kuchi & Mwanza & $-2.85^{\circ}, 33.083^{\circ}$ & 1363 & 23.3 & $76 \%$ \\
& Singida & $-5.483^{\circ}, 34.483^{\circ}$ & 1508 & 22.0 & $74 \%$ \\
Morogoro-medium & Morogoro & $-5.5^{\circ}, 34.5^{\circ}$ & 213 & 24.6 & $75 \%$ \\
& Tanga & $-5.0667^{\circ}, 39.1^{\circ}$ & 22 & 28.0 & $76 \%$ \\
\hline
\end{tabular}

${ }^{\mathrm{a}}$ Average temperature per year, ${ }^{\mathrm{b}}$ Average humidity per year 


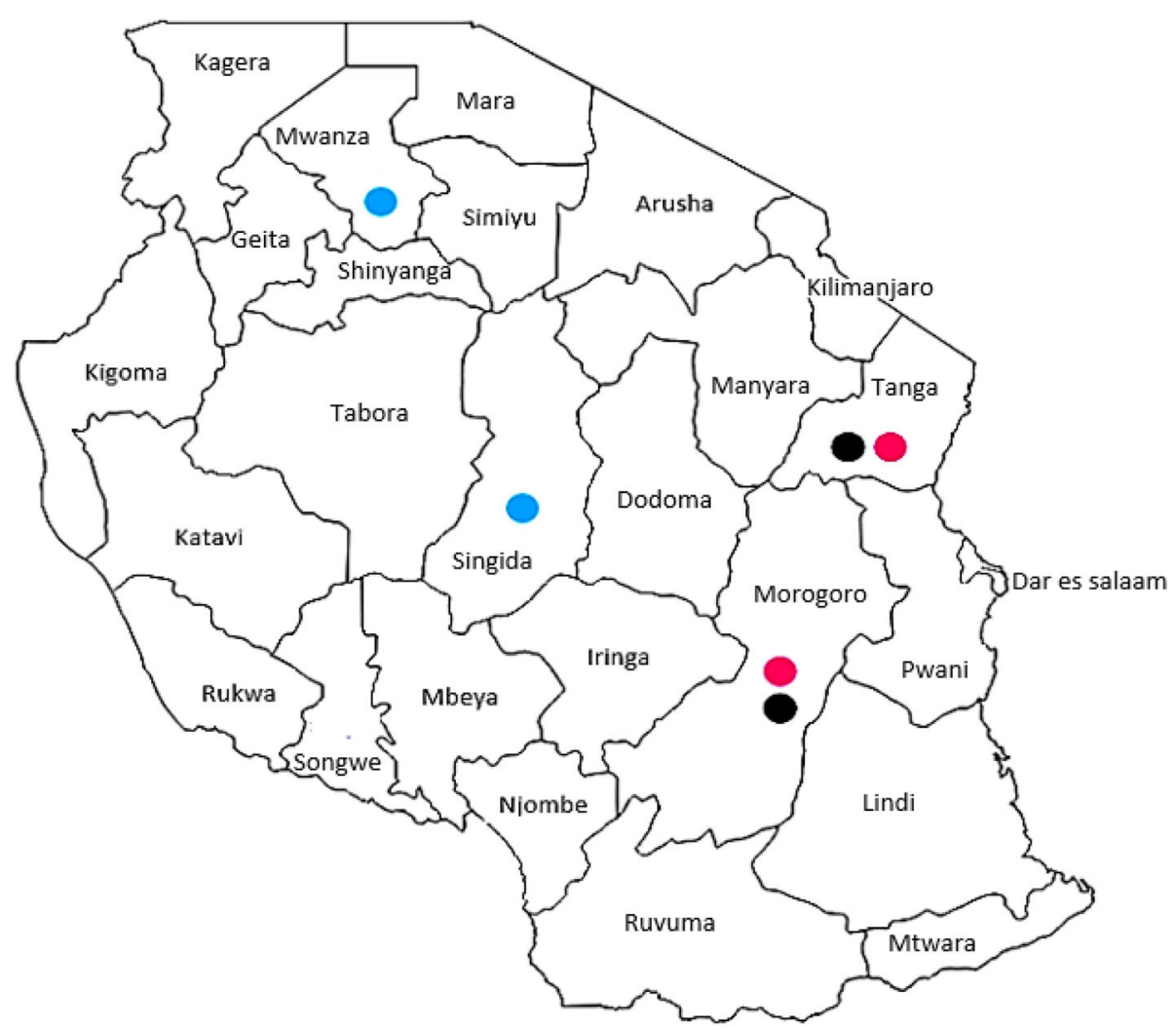

Fig. 4 Geographical origins of Kuchi (blue), Morogoro-medium (purple) and Ching'wekwe (Black) chickens in Tanzania (https://d-maps.com/carte.php?num_car=36219\&lang=en, 2/3/2020)

as described by Geuye et al. [31]. In brief, the body length (BL), neck length (NL), chest girth (CG), shank length (SL) and shank girth (SG) were measured in centimetres $(\mathrm{cm})$ for each chicken using a tailor's measuring tape (Fig. 5) [32]. The body weights (BW) of the chickens were measured in grams (gm) using a $0.01 \mathrm{~g}$ sensitive electronic weighing scale. The linear measurements were performed as follows; BL was measured as the distance from tip of the beak through the dorsum of the chicken to the base of the tail, the NL from the base of the head to the shoulder at the clavicle, CG as the circumference of the chest in front of the thighs, SL as the distance from the hock joint to the metatarsal pad and the $\mathrm{SC}$ as the circumference of the middle part of the metatarsus.

\section{Population structure analysis}

At 21 days of age, blood samples were collected from each chick by pricking the basilic vein. Approximately five drops of blood were dried on FTA cards (Whatman Biosciences, Brentford, UK) labelled with the chicken's wing tag number and stored at room temperature. Section cuts $(3 \times 3 \mathrm{~mm}$ ) using a scalpel blade were made in the cards for each chicken. The scalpel blade was decontaminated in between chickens via flaming. DNA was extracted and precipitated in sodium acetate ethanol using the phenol-chloroform method [33]. A total of 1399 birds were genotyped using a chicken $600 \mathrm{~K}$ SNP Panel at GeneSeek, USA, and quality control (QC) was performed using the Axiom ${ }^{\mathrm{Tm}}$ Analysis Suite Software version 3.1 (Applied Biosystems, Thermo Fisher Scientific Inc., Calsbad, CA, USA) as explained by Walugembe et al. [34]. Briefly, Gallus gallus genome version 5 (Thermo Fisher Scientific Inc., Calsbad, CA, USA) chicken genome files were used for comparison during the genotyping of the FRLC. During quality control, SNP set with number of clusters $\geq 2$, call rates $\geq 99 \%$ and minor allele frequency $\geq$ 0.05 were selected for downstream analyses. Other quality control metrics and imputation of missing genotypes are explained further in Walugembe et al. [34]. A total of 396, 055 SNPs remained for further downstream analyses. Determination of the structure of the populations was performed using the admixture software [35] as explained in Walugembe et al. [34] where briefly, SNPs with closest ancestry were determined using varying values of $\mathrm{k}$ (sub-populations) ranging from 1 to 4 and the final $\mathrm{k}$ value $(\mathrm{k}=2)$ 


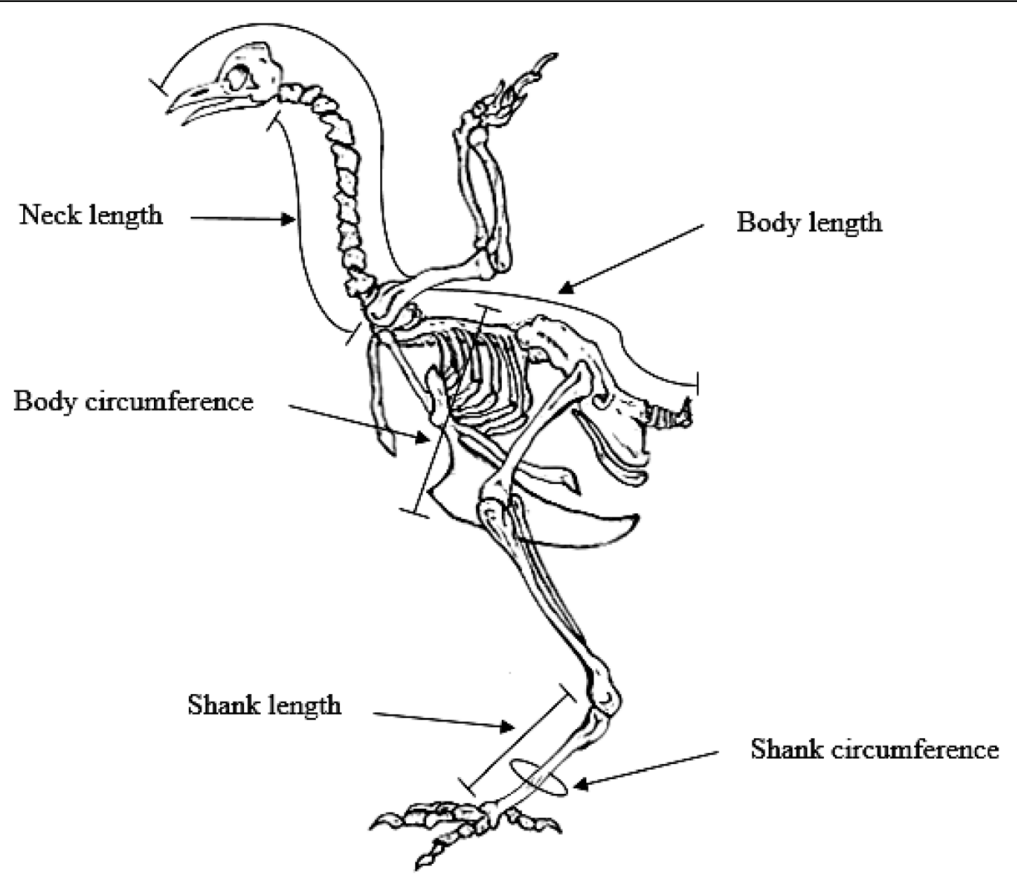

Fig. 5 Pictorial representation of where various linear body measurements were taken from Tanzanian chickens for their characterization (http://10.tbhy.allovero.fr/diagram-of-chicken-bone.html, 2/3/2020)

was determined based on the lowest cross-validation error. The population structure was also determined using multidimensional scaling in plink [36] in two dimensions as shown by Walugembe et al. [34]. At the end of the studies, the chickens were humanely euthanized according to published guidelines [37] and the UC Davis IACUC (\# 20831) protocol.

\section{Statistical analysis}

The linear measurements were compared among the three chicken ecotypes using $\mathrm{R}$ - Statistical Software Program version 3.5.1 [38]. Analyses of variances (one way ANOVA) of the least square means with associated standard errors (LSmeans \pm SE) of the measurements were used to assess for differences among the three chicken ecotypes. Differences were considered significant at $p \leq 0.05$ using the Tukey honestly significant difference (Tukey HSD). The linear model to test the effects of the chicken ecotype and sex on the lengths of the measured body parts was as follows:

$$
\mathrm{Y}_{\mathrm{ijk}}=\mu+\mathrm{G}_{\mathrm{i}}+\mathrm{A}_{\mathrm{j}}+(\mathrm{GA})_{\mathrm{ijk}}+\mathrm{e}_{\mathrm{ijk}}
$$

where:

$\mathrm{Y}_{\mathrm{ijk}}=$ trait response variable

$\mu=$ general population mean for trait response

$G_{i}=$ effect of the sex on the trait of an ecotype
$A_{j}=$ effect of the ecotype on the trait

(GA)ijk = effect of interaction between sex of chicken and its ecotype

$\mathrm{e}_{\mathrm{ij}}=$ effect of random experimental errors on the trait response

\section{Abbreviations \\ IACUC: Institutional Animal Care and Use Committee; FRLC: Free-range Local Chickens; ND: Newcastle disease; UCDavis: University of California Davis; USAID: United States Agency for International Development; \\ DNA: Deoxyribonucleic Acid; SNP: single nucleotide polymorphism; MDS: multi-dimensional scaling; LSmeans: Least square means; Tukey HSD: Tukey honesty significant difference; ANOVA: Analyses of variance; QC: quality control; IBD: infectious bursal disease; SUA: Sokoine University of Agriculture; DAARS: Department of Animal, Aquaculture and Range Sciences}

\section{Acknowledgements}

We acknowledge the University of California Davis (UC Davis) and lowa State University technical support in the research and Sokoine University of Agriculture in Tanzania for approving and providing an environment conducive for conducting the research.

\section{Authors' contributions}

All authors read and approved the manuscript. JM analyzed the linear phenotype measurements and was the primary author of the manuscript, GC and EM were responsible for preparation of the experimental chickens, and data collection, MW conducted the structure analysis from the SNP genotypes and participated in all phases of the paper write up from conceptualization, analysis to the final write up, EA participated in the structure analysis, $\mathrm{HZ}$ is the principle investigator for the Genomics to Improve Poultry Innovation Lab, AM is the principle investigator for this study, PM, RM, HZ, JD, SL, TK and RG participated in the conceptualization of the study and the review of the manuscript drafts before final submission to the journal. 


\section{Funding}

This study was made possible by the generous support of the American people through the United States Agency for International Development (USAID) Feed the Future Innovation Lab for Genomics to Improve Poultry (cooperative agreement number AID-OAA-A-13-00080). The funding body had no role in the design, analyses, interpretation or writing of this manuscript. The contents are the responsibility of the Feed the Future Innovation Lab for Genomics to Improve Poultry and do not necessarily reflect the views of USAID or the United States Government.

\section{Availability of data and materials}

The datasets supporting the conclusions of this article are available in the USAID Data Development Library (DDL) repository, and can be accessed publicly at the https://www.usaid.gov/development-data-library request.

\section{Ethics approval and consent to participate}

The study was approved by the research committee of the Sokoine University of Agriculture and the University of California Davis and followed the Institutional Animal Care and Use Committee (IACUC) protocol of University of California Davis (\# 20831) to conduct experiments.

\section{Consent for publication}

Not applicable.

\section{Competing interests}

The authors declare that they have no competing interests.

\section{Author details}

${ }^{1}$ Department of Veterinary Medicine and Public Health, Sokoine University of Agriculture, Morogoro, Tanzania. ${ }^{2}$ Department of Animal Science, University of Ghana, Accra, Ghana. ${ }^{3}$ Department of Animal Science, lowa State University, Ames, IA 50011, USA. ${ }^{4}$ School of Veterinary Medicine, University of California, Davis 95616, USA. ${ }^{5}$ Department of Animal Science, University of California, Davis 95616, USA.

Received: 7 February 2020 Accepted: 25 August 2020

Published online: 29 September 2020

\section{References}

1. Gueye EF. Poultry plays an important role in African village life. World Poultry. 1998;14(10):14-7.

2. Swai ES, Karimuribo ED, Kyakaisho PF, Mtui PF: Free-range village chickens on the humid coastal belt of Tanga, Tanzania: their roles, husbandry and health status. Livest Res Rural Dev, 2007; 19(8). http://www.Irrd.org//rrd19/8/ swai19104.htm. Accessed 25 March 2020.

3. Kabatange MA, Katule AM. Rural poultry production systems in Tanzania Proceedings of an International Workshop on Rural Poultry in Africa. Nigeria 13-16 November 1989. Ile-Ife: Food and Agriculture Organization (FAO) of the United Nations Rome; 1998. p. 171-6.

4. Lweramila J, Kifaro GC, Gwakisa PS. On station and on-farm evaluation of two Tanzania chicken ecotypes for body weights at different ages and for egg production. Afr J Agric Res. 2008;3(12):843-51.

5. Gwakisa PS, Katule AM, Rugaimukamu EA. Divergent immune responses to Newcastle disease virus vaccination of rural chicken in Tanzania. Tanzania Vet J. 1994:43:171-6.

6. Msoffe PL, Minga UM, Olsen JE, Yongolo MG, Juul-Madsen HR, Gwakisa PS, Mtambo MM. Phenotypes including immunocompetence in scavenging local chicken ecotypes in Tanzania. Trop Anim Health Production. 2002; 33(4):341-54.

7. Ogie AJ, Salako AE, Emikpe BO, Amosun EA, Adeyemo SA, Akinoluwa PO. The comparative susceptibility of commercial and Nigerian indigenous chicken ecotypes to Salmonella gallinarum infection. Sokoto J Vet Sci. 2013; 11(2):49-56

8. Fleming DS, Weigend S, Simianer H, Weigend A, Rothschild M, Schmidt C, Lamont SJ. Genomic Comparison of Indigenous African and Northern European Chickens Reveals Putative Mechanisms of Stress Tolerance Related to Environmental Selection Pressure. G3: Genes Genomes Genetics. 2017; 7(5):1525-37.

9. Kondombo SR, Nianogo AJ, Kwakkel RP, Udo HM, Slingerland M. Comparative analysis in village chicken production in two farming systems in BurkinaFaso. Trop Anim Health Prod. 2003;35(6):563-74.
10. Msoffe PLM, Mtambo MMA, Minga UM, Olsen JE, Juul-Madsen HR,Gwakisa PS, Mutayoba SK, Katule AM: Productivity and reproductive performance of the free-range local domestic fowl ecotypes in Tanzania. Livestock Research for Rural Development, 2004; 16 (art. \#69). http://www.cipav.org.co//rrd/ Irrd16/9/msof16067.htm. Accessed 25 March 2020.

11. Guni FS, Katule AM: Characterization of local chickens in selected districts of the Southern Highlands of Tanzania: I. Qualitative characters. Livestock Research for Rural Development, 2013; 25 (art \#190). http://www.lrrd.org/ Irrd25/11/guni25190.htm. Accessed 25 March 2020.

12. Alabi OJ, Ng'ambi JW, Norris D, Egena SSA. Comparative study of three indigenous breeds of South Africa: body weight and linear body measurements. Agric J. 2012;7(3):220-5.

13. Francesch A, Villalba I, Cartañà M. Methodology for morphological characterization of chicken and its application to compare Penedesenca and Empordanesa breeds. Anim Genetic Resources. 2011;48:79-84.

14. Hosny FA: The structure and importance of the commercial and villagebased poultry system in Egypt 139 poultry sector country review food and agricultural Organization of the United Nations), FAO Rome, 2006. http:// www.fao.org/docs/eims/upload/228579/poultrysector_egy_en.pdf. Accessed 11 July 2019.

15. Msoffe PLM, Mtambo MMA, Minga UM, Juul-Madsen HR, Gwakisa PS. Genetic structure among the local chicken ecotypes of Tanzania based on microsatellite DNA typing. Afr J Biotechnol. 2005;4(8):768-71.

16. Mwacharo JM, Bjørnstad G, Mobegi V, Nomura K, Hanada H, Amano T, Jianlin $\mathrm{H}$, Hanotte $\mathrm{O}$. Mitochondrial DNA reveals multiple introductions of domestic chicken in East Africa. J Mol Phylogenetics Evol. 2011;58(2): 374-82.

17. Lyimo CM, Weigend A, Janßen-Tapken U, Msoffe PL, Simianer H, Weigend S. Assessing the genetic diversity of five Tanzanian chicken ecotypes using molecular tools. South Afr J Anim Sci. 2013;43(4):499-510.

18. Hillel J, Granevitze Z, Twito T, Ben-avraham D, Blum S, Lavi U, Feldman MW $\mathrm{DL}$, Cheng $\mathrm{H}$, Weigend S. Molecular markers for the assessment of chicken biodiversity. World's Poultry Sci J. 2007;63(1):33-45.

19. Elferink MG, Megens HJ, Vereijken A, Hu X, Crooijmans RP, Groenen MA. Signatures of selection in the genomes of commercial and non-commercial chicken breeds. PLoS One. 2012;7(2):e32720.

20. Ritzyan, Katano T, Shimogiri T, Kawabe K, Okamoto S. Genetic diversity and population structure of Indonesian native chickens based on single nucleotide polymorphism markers. Poult Sci. 2011;90(11):2471-8.

21. King C and Stanfield WD: Dictionary of genetics. Oxford. "Panmixia (panmixis): random mating as contrasted with assortative mating." 1997. https://en.wikipedia.org/wiki/Panmixia. Accessed 2 Apr.2019.

22. Vera FM. Expanding production of indigenous day-old chicks' production. A one-day meeting of hatchery owners hatching indigenous chickens. Dar esSalaam: Regency Park Hotel; 2011.

23. Magonka JM, Sendalo DS, Goromela EH, Malingila, PB and Daniel E: Production Performance of Indigenous Chickens under Semi Intensive Management Conditions in Central Tanzania. Huria: Journal of the Open University of Tanzania, 2016, 22(1). https://www.ajol.info/index.php/huria/ article/viewFile/152641/142230. Accessed 5 Apr.2019.

24. Nobo G, Moreki JC, Nsoso SJ. Feed intake, body weight, average daily gain, feed conversion ratio and carcass characteristics of helmeted Guinea fowl fed varying levels of Phane meal (Imbrasia belina) as replacement of fishmeal under intensive system. Int J Poult Sci. 2012;11(6):378-84.

25. Drobney RD. Body weight and composition changes and adaptations for breeding in wood ducks. Condor. 1982;84(3):300-5.

26. Oka T, Ino Y, Nomura K, Kawashima S, Kuwayama T, Hanasa H, Amano T, Takada M, Takahata N, Hayashi Y, Akishinonomiva F. Analysis of mtDNA sequences shows Japanese native chickens have multiple origins. Anim Genetical. 2007;38(3):287-93.

27. Komiyama T, Ikeo K, Gojobiri T. Where is the origin of the Japanese gamecocks? Gene. 2003;317(1-2):195-202.

28. Tanzania free map, free blank map, free outline map, free base map. https://d-maps.com/carte.php?num_car=36219\&lang=en.htm Accessed 2Apr.2019.

29. Minga UM, Nkini RP. Diseases as a major constraint to chicken production in Tanzania. In: Proceedings of the $13^{\text {th }}$ scientific conference of the TSAP, held at Arusha AICC, vol. 13; 1986. p. 284-92.

30. Yongolo MGS. Epidemiology of Newcastle disease in village chickens in Tanzania. MVM Dissertation, vol. 230. Morogoro: Sokoine University of Agriculture; 1996. 
31. Gueye EF, Ndiaye A, Branckaert RDS. Prediction of mature body weight on the basis of body measurement in mature indigenous chickens in Senegal. Livest Res Rural Dev. 1998;10 http://www.Irrd.org//rrd10/3/sene103.htm. Accessed 4 Oct.2019.

32. http://10.tbhy.allovero.fr/diagram-of-chicken-bone.html. Accessed 2 Oct.2019.

33. Sambrook J, Russel DW. Purification of nucleic acids by extraction with phenol:chloroform. Cold Spring Harb Protoc NY. 2006.

34. Walugembe M, Mushi JR, Amuzu-Aweh EN, Chiwanga GH, Msoffe PL, Wang Y, Saelao P, Kelly T, Gallardo RA, Zhou H, Lamont SJ, Muhairwa AP, Dekkers JCM. Genetic analyses of Tanzanian local chicken ecotypes challenged with Newcastle disease virus. Genes (Basel). 2019;10(7):546.

35. Alexander DH, Novembre J, Lange K. Fast model-based estimation of ancestry in unrelated individuals. Genome Res. 2009;19(9):1655-64.

36. Chang CC, Chow CC, Tellier LC, Vattikuti S, Purcell SM, Lee JJ. Secondgeneration PLINK: rising to the challenge of larger and richer datasets. Gigascience. 2015;4:7 https://www.ncbi.nlm.nih.gov/pmc/articles/PMC43421 93/\#. Accessed 25 March 2020.

37. Patricia H, Chair KA, Inma E, Ken K, Sally N, Robert P, Carl MT, Bruce W. Poultry In: Guide for the care and use of agricultural animals in research and teaching. Champaign: FASS Inc.; 2010. p. 102-20. Available at http://www. fass.org.

38. R Core Team R: A language and environment for statistical computing. $R$ Foundation for Statistical Computing, Vienna, Austria, (2013). URL http:// www.r-project.org/. Accessed 5 Apr.2019.

\section{Publisher's Note}

Springer Nature remains neutral with regard to jurisdictional claims in published maps and institutional affiliations.

Ready to submit your research? Choose BMC and benefit from:

- fast, convenient online submission

- thorough peer review by experienced researchers in your field

- rapid publication on acceptance

- support for research data, including large and complex data types

- gold Open Access which fosters wider collaboration and increased citations

- maximum visibility for your research: over $100 \mathrm{M}$ website views per year

At $\mathrm{BMC}$, research is always in progress.

Learn more biomedcentral.com/submissions 